ORIGINAL ARTICLE

\title{
KOMORBIDITAS GANGGUAN PEMUSATAN PERHATIAN DAN HIPERAKTIVITAS PADA ANAK
}

\author{
Olga Fanny Tantiwi Nurdin* \\ Fakultas Kedokteran, Universitas Mulawarman \\ *Correspondent author: olgafanny36@gmail.com
}

\section{ARTICLE INFO \\ Article history: \\ Submission: July \\ 262019 \\ Received in revised \\ form \\ August 2019 \\ Accepted: August \\ 212019}

\begin{abstract}
Attention Deficit Hyperactivity Disorder (ADHD) is the most frequent case that parents take to seek treatment at a child psychiatrist. Many ADHD children referred to the hospital showed additional disorders that accompanied the main diagnosis which served as comorbidity. It is important to detect the presence of comorbidity in children with ADHD because it can be a diagnostic challenge, as the manifestation is more complex and the prognosis is worse than those with ADHD alone. The aim of this study was to explore the types of comorbid disorders and its risk factors in paediatric patients with ADHD. This study used a quantitative descriptive method, with a total sampling technique. This study was done at Atma Husada a district psychiatric hospital (RSJD), Mahakam Samarinda in 2015-2018 period. Total samples were 84 cases. Our results showed that 18 cases $(21 \%)$ were without comorbid, 52 cases $(62 \%)$ had 1 comorbid and 14 cases (17\%) were had > 1 comorbids. Autism Spectrum Disorder (ASD) was the most common type of comorbid disorder which showed 28 cases (35\%). The most prominent risk factors in ADHD with comorbidity were natal factors which mean abnormalities during childbirth $(39 \%)$ and partial parenting factors of $(18 \%)$. While in ADHD without comorbidity, the most prominent risk factor was postnatal factors $(33 \%)$ and there was no case partial parenting factor. The benefit of this study is by knowing the presence of comorbidities, it is expected a careful initial evaluation must be carried out during diagnostics to eliminate various possible differential diagnoses and it is also expected that the comorbidities accompany GPPH can be handled properly.
\end{abstract}

\begin{abstract}
ABSTRAK
Gangguan Pemusatan Perhatian dan Hiperaktivitas (GPPH) merupakan bagian terbesar dari anak yang dibawa orangtua untuk berobat ke psikiater anak. Anak GPPH yang dirujuk ke klinik banyak yang menunjukkan gangguan lain yang menyertai diagnosis utama yang disebut sebagai komorbiditas. Sangat penting untuk mendeteksi kehadiran komorbiditas ketika anak didiagnosis GPPH karena dapat menjadi tantangan diagnostik, manifestasi akan lebih kompleks serta prognosis akan lebih buruk dibandingkan dengan anak-anak dengan GPPH saja. Tujuan penelitian untuk mengetahui jenis gangguan komorbid pasien anak GPPH dan faktor risiko pasien anak GPPH. Penelitian ini menggunakan desain deskriptif kuantitatif, dengan teknik total sampling. Penelitian ini dilakukan di RSJD Atma Husada Mahakam Samarinda periode 2015-2018. Total sampel adalah 84 kasus. Hasil menunjukkan bahwa 18 kasus (21\%) tanpa komorbid, 52 kasus (62\%) memiliki 1 komorbid dan 14 kasus (17\%) yang memiliki >1 komorbid. Gangguan Spektrum Autisme (GSA) merupakan jenis gangguan komorbid terbanyak yaitu terdapat 28 kasus $(35 \%)$. Faktor risiko yang paling menonjol dari pasien anak GPPH dengan komorbiditas adalah faktor natal atau faktor kelainan saat persalinan (39\%) dan faktor pengasuhan parsial (18\%). Faktor risiko yang paling menonjol dari pasien anak GPPH tanpa komorbiditas adalah faktor postnatal $(33 \%)$ dan tidak adanya kasus faktor pengasuhan parsial. Manfaat dari studi ini adalah dengan mengetahui adanya komorbiditas diharapkan evaluasi awal yang cermat harus dilakukan saat diagnostik untuk mengeliminasi berbagai kemungkinan diagnosa banding dan diharapkan juga komorbiditas yang menyertai GPPH dapat ditangani dengan baik.
\end{abstract}




\section{PENDAHULUAN}

Gangguan Pemusatan Perhatian dan Hiperaktivitas (GPPH) merupakan kasus terbanyak pada anak yang dibawa orangtuanya untuk berobat ke psikiater anak. Keluhan utama orang tua tersebut adalah bahwa anak mereka "nakal", "malas belajar", dan "kurang konsentrasi", baik di sekolah ataupun di rumah ${ }^{1}$.

Penelitian terdahulu pada 30 sekolah dasar yang terpilih secara acak di Jakarta tahun 2011, didapatkan angka proporsi GPPH sebesar 26,2\%. Penelitian lain yang dilakukan di Bali tahun 2012 menunjukkan jumlah pasien GPPH yang berkunjung ke poliklinik Tumbuh Kembang Rumah Sakit Umum Pemerintah (RSUP) Sanglah sebanyak 63 orang. Anak laki-laki dikatakan memiliki insidensi yang lebih tinggi untuk mengalami GPPH daripada perempuan, dengan rasio sebesar 3-4: $1^{2}$.

Komorbiditas adalah suatu keadaan yang menunjukkan terdapat dua penyakit yang berbeda dalam waktu yang bersamaan dalam diri seseorang ${ }^{3}$. Menurut Saputro (2009) pasien anak GPPH yang dirujuk ke klinik banyak yang menunjukkan gangguan psikiatri lain, seperti gangguan sikap menentang, gangguan tingkah laku, gangguan suasana perasaan, gangguan kecemasan, gangguan belajar dan gangguan komunikasi, juga Tourette syndrome. Gangguangangguan lain yang menyertai GPPH ini dapat berlanjut sampai remaja bahkan sampai dewasa jika tidak mendapat penanganan yang adekuat ${ }^{1}$.

Penelitian sebelumnya oleh Ratnasari, Kaunang, Dundu tahun 2015-2016 di Kota Manado yang dilakukan terhadap 20 Sekolah Dasar didapatkan bahwa dari 611 siswa yang terskrining GPPH, 143 diantaranya mempunyai komorbiditas. Kasus komorbiditas yang terbanyak adalah gangguan perilaku oposisional menentang 4 .

Berdasarkan sejumlah penelitian di atas, tampaknya angka kejadian adanya komorbiditas pada pasien GPPH anak cukup besar, sehingga penting untuk dilakukan deteksi adanya komorbiditas saat diagnosis GPPH dilakukan. Melihat pada psikopatologis terkait GPPH dengan komorbiditas, manifestasi klinis akan lebih kompleks daripada GPPH tanpa komorbiditas \& dapat menjadi tantangan diagnostik. Oleh karena itu, evaluasi awal yang cermat perlu dilakukan untuk mengeliminasi berbagai kemungkinan diagnosis banding. Sebagai tambahan, prognosis dan hasil akhir dari anak-anak dengan komorbid pada GPPH lebih buruk dibandingkan dengan anak-anak dengan GPPH saja ${ }^{5}$.

Tujuan penelitian ini untuk mengetahui jenis gangguan komorbid pasien anak GPPH, serta untuk mengetahui ada tidaknya perbedaan faktor risiko pasien anak GPPH dengan dan tanpa komorbiditas.

\section{METODE PENELITIAN}

Penelitian ini menggunakan desain penelitian deskriptif kuantitatif. Populasi dalam penelitian ini adalah semua rekam medik pasien anak yang memiliki diagnosis GPPH di RSJD Atma Husada Mahakam Samarinda periode tahun 2015-2018. Variabel dalam penelitian ini yaitu jenis kelamin dan usia sebagai karakteristik; berbagai komorbiditas; riwayat keluarga, faktor prenatal, faktor natal, faktor postnatal, dan pola pengasuhan parsial sebagai faktor risiko.

\section{HASIL}

Karakteristik pasien yang diikutkan dalam studi ini adalah jenis kelamin yang didapatkan terbanyak yaitu perempuan (87\%). Karakteristik lain yang diikutkan adalah usia dengan pembagian kategori berdasarkan American Academy of Pediatrics $(2011)^{6}$. didapatkan kategori terbanyak yaitu usia toddler (40\%) seperti yang tampak pada tabel 1. berikut ini :

Tabel 1. Karakteristik Pasien Anak dengan GPPH

\begin{tabular}{lcc}
\hline \multicolumn{1}{c}{ Karakteristik } & $(\mathrm{n})$ & $(\%)$ \\
\hline 1. Jenis Kelamin & & \\
Laki-Laki & 11 & 13 \\
Perempuan & 73 & 87 \\
& 84 & 100 \\
2. Usia & & \\
0-12 bulan (infant) & 0 & 0 \\
13 bulan-3 tahun & 34 & 40 \\
(toddler) (unekolah) & 25 & 30 \\
4-5 tahun (prasek & \\
6-12 tahun (usia sekolah) & 25 & 30 \\
& 84 & 100 \\
\hline
\end{tabular}


Dari sampel rekam medik diperoleh total sampel adalah sebanyak 84 pasien. Banyaknya pasien dengan komorbiditas adalah sebesar $79 \%$. Pasien umumnya menunjukkan adanya 1 komorbiditas (62\%) (tabel 2.).

Tabel 2. Komorbiditas Pasien Anak dengan GPPH

\begin{tabular}{lll}
\hline Komorbiditas & $(\mathrm{n})$ & $(\%)$ \\
\hline Tidak ada komorbid & 18 & 21 \\
1 komorbid & 52 & 62 \\
$>1$ komorbid & 14 & 17 \\
Total & 84 & 100 \\
\hline
\end{tabular}

Adapun jenis gangguan komorbid terbanyak yang menyertai pasien antara lain gangguan spektrum autism (35\%), gangguan berbicara dan berbahasa $(28 \%)$ serta retardasi mental $(16 \%)$.

Jenis komorbid lainnya dapat dilihat pada tabel 3 .

Tabel 3. Jenis Gangguan Komorbid

\begin{tabular}{lcc}
\hline Komorbiditas & (n) & $(\%)$ \\
\hline Gangguan Spektrum Autisme & 28 & 35 \\
Gangguan Berbicara dan & 23 & 28 \\
Berbahasa & & \\
Retardasi Mental & 13 & 16 \\
Disruptive, Impulse-Control, & 5 & 6 \\
and Conduct Disorders & & \\
Gangguan Koordinasi Motorik & 5 & 6 \\
Halus dan Kasar & & \\
Gangguan Kecemasan & 4 & 5 \\
Gangguan Pendengaran & 1 & 1 \\
Gangguan Sensori Integrasi & 1 & 1 \\
Epilepsi & 1 & 1 \\
\hline
\end{tabular}

Dari 14 pasien yang mempunyai komorbid $>1$, gangguan berbicara dan berbahasa yang disertai retardasi mental merupakan gejala terbanyak (29\%). Keluhan komorbid lain dapat dilihat pada tabel 4 .

Tabel 4. Jenis Gangguan >1 Komorbid

\begin{tabular}{lcc}
\hline \multicolumn{1}{c}{$>1$ Komorbiditas } & (n) & (\%) \\
\hline $\begin{array}{l}\text { Gangguan Berbicara dan Berbahasa + } \\
\text { Retardasi Mental }\end{array}$ & 4 & 29 \\
$\begin{array}{l}\text { Gangguan Spektrum Autisme + } \\
\text { Retardasi Mental }\end{array}$ & 3 & 22 \\
$\begin{array}{l}\text { Gangguan Spektrum Autisme + } \\
\text { Gangguan Koordinasi Motorik Halus dan }\end{array}$ & 2 & 14 \\
$\begin{array}{l}\text { Kasar } \\
\text { Gangguan Spektrum Autisme + } \\
\text { Disruptive, Impulse-Control, and } \\
\text { Conduct Disorders }\end{array}$ & 1 & 7 \\
\cline { 1 - 1 } & & \\
\end{tabular}

\begin{tabular}{lll}
\hline Gangguan Spektrum Autisme + & 1 & 7 \\
Gangguan Kecemasan & & \\
$\begin{array}{l}\text { Gangguan Kecemasan + Gangguan } \\
\text { Sensori Integrasi }\end{array}$ & 1 & 7 \\
$\begin{array}{l}\text { Gangguan Kecemasan + Retardasi } \\
\text { Mental }\end{array}$ & 1 & 7 \\
$\begin{array}{l}\text { Epilepsi + Gangguan Koordinasi } \\
\text { Motorik Halus Dan Kasar + Retardasi } \\
\text { Mental }\end{array}$ & & 7 \\
\hline
\end{tabular}

Retardasi mental tampaknya merupakan kombinasi yang sering menyertai komorbiditas $>1$. Adapun distribusi derajat retardasi mental yang ada dapat dilihat pada tabel 5. Derajat retardasi berkisar dari ringan sampai berat, namun tidak ada yang sangat berat.

Tabel 5. Derajat Retardasi Mental

\begin{tabular}{lcc} 
Derajat Retardasi Mental & $(\mathrm{n})$ & $(\%)$ \\
\hline Ringan & 4 & 30 \\
Sedang & 8 & 62 \\
Berat & 1 & 8 \\
Sangat Berat & 0 & 0 \\
Total & 13 & 100
\end{tabular}

Hasil penelitian ini menunjukkan bahwa dari semua faktor risiko pada pasien anak GPPH dengan komorbiditas, terlihat faktor natal merupakan faktor terbesar yaitu sebanyak 39\%. Proses kelahiran dengan metode sectio caesarea menjadi faktor natal terbanyak (20\%). Selain itu, terdapat juga faktor risiko pengasuhan parsial sebanyak 18\% (tabel 6.)

Tabel 6. Faktor Risiko GPPH Dengan Komorbiditas

\begin{tabular}{llcc} 
& Sementara itu, & penelitian & ini \\
\hline & Faktor Risiko & $(\mathrm{n})$ & $(\%)$ \\
\hline 1. & Riwayat Keluarga & 1 & 6 \\
2. & Faktor Prenatal & 2 & 11 \\
3. & Faktor Natal & & \\
- & BBLR & 0 & 0 \\
- & Prematur & 2 & 11 \\
- & Sectio Caesarea & 2 & 11 \\
& & 4 & 22 \\
4. & Faktor Postnatal & & \\
- & Riwayat Kejang Demam & 2 & 11 \\
- & Riwayat Trauma Kepala & 4 & 22 \\
& & 6 & 33 \\
5. & Pengasuhan Parsial & 0 & 0 \\
\hline
\end{tabular}


menunjukkan bahwa pada pasien anak GPPH tanpa komorbiditas mempunyai faktor risiko yang berbeda dengan yang disertai komorbiditas. Faktor risiko terbanyak adalah faktor postnatal (33\%). Terlihat juga adanya perbedaan bahwa tidak didapatkannya faktor risiko pengasuhan parsial untuk pasien anak GPPH tanpa komorbiditas (tabel 7.).

Tabel 7. Faktor Risiko GPPH Tanpa Komorbiditas

\begin{tabular}{|c|c|c|c|}
\hline \multicolumn{2}{|c|}{ Faktor Risiko } & \multirow{2}{*}{$\frac{(\mathrm{n})}{3}$} & \multirow{2}{*}{$\frac{(\%)}{5}$} \\
\hline 1. & Riwayat Keluarga & & \\
\hline 2. & Faktor Prenatal & 5 & 8 \\
\hline 3. & Faktor Natal & & \\
\hline - & BBLR & 7 & 11 \\
\hline - & Prematur & 5 & 8 \\
\hline \multirow[t]{2}{*}{ - } & Sectio Caesarea & 13 & 20 \\
\hline & & 25 & 39 \\
\hline 4. & Faktor Postnatal & & \\
\hline - & $\begin{array}{l}\text { Riwayat Kejang } \\
\text { Demam }\end{array}$ & 10 & 15 \\
\hline \multirow[t]{2}{*}{ - } & Riwayat Trauma & 3 & 5 \\
\hline & & 13 & 20 \\
\hline 5 & Pengasuhan Parsial & $\underline{12}$ & 18 \\
\hline
\end{tabular}

\section{PEMBAHASAN}

Hasil penelitian ini menunjukkan bahwa persentase anak GPPH yang memiliki komorbid sebesar $79 \%$. Hasil penelitian ini sesuai dengan studi epidemiologi yang menunjukan tingkat komorbiditas antara 50\% sampai $90 \%$ untuk anak GPPH ${ }^{7}$. Pada penelitian ini juga sesuai dengan yang dilakukan oleh Patel et al., (2011) yang menunjukkan adanya komorbiditas sebesar $67 \%$ yang terdiri atas satu komorbiditas sebanyak 33\%, dua komorbiditas sebanyak $16 \%$ dan yang memiliki tiga atau lebih komorbiditas sebanyak $18 \%$. Patel juga menyatakan bahwa adanya komorbiditas pada pasien GPPH anak mengakibatkan hasil yang sangat buruk, terutama jika komorbiditas itu sendiri terkait dengan gangguan jiwa lainnya ${ }^{8}$.

Komorbiditas GSA yang didapatkan memiliki frekuensi paling banyak dengan jumlah
28 kasus dengan persentase sebesar 35\%. Hal ini sesuai dengan penelitian yang dilakukan oleh Leitner yang mendapatkan prevalensi komorbid GSA 31\% pada anak-anak sekolah dasar. Terdapat bukti adanya keterkaitan antara GPPH dengan GSA mempengaruhi risiko berat ringannya masalah psikososial pada anak ${ }^{9}$. GSA seringkali ditemukan bersamaan dengan GPPH. Anak yang menderita GSA seringkali menunjukkan gejala hiperaktif, sulit berkonsentrasidan impulsif, sebaliknya anak yang menderita GPPH juga sering mengalami gangguan interaksi sosial ${ }^{10}$.

Pada penelitian ini gangguan berbicara dan berbahasa bersamaan dengan retardasi mental merupakan komorbiditas >1 komorbid terbanyak dengan persentase $29 \%$. Kemampuan berbahasa merupakan indikator seluruh perkembangan anak, karena kemampuan berbahasa sensitif terhadap keterlambatan atau kelainan pada sistem lainnya, seperti kemampuan kognitif, sensorimotor, psikologis, emosi dan lingkungan di sekitar anak. Oleh karena itu, gangguan berbahasa juga sangat terkait dengan retardasi mental atau yang biasa dikenal dengan disabilitas intelektual ${ }^{11}$. Anakanak GPPH dengan retardasi mental memiliki prevalensi 3 kali lebih banyak dibandingkan dengan anak-anak populasi umum dengan retardasi mental saja ${ }^{12}$.

Faktor risiko terbanyak yang didapatkan untuk pasien anak GPPH dengan komorbiditas adalah faktor natal $(39 \%)$ yang terbagi menjadi BBLR, Prematur, dan Sectio Caesarea. Suatu penelitian kasus kontrol menyebutkan bahwa faktor natal (prematur, BBLR, sectio caesarea) merupakan faktor resiko GPPH yang dapat memicu timbulnya GPPH ataupun memperparah gejala klinis GPPH ${ }^{13}$.

Terlihat juga terdapat faktor pengasuhan parsial pada pasien anak GPPH dengan komorbiditas pada penelitian ini. Adanya masalah dan ketidaknyamanan dalam lingkungan keluarga merupakan faktor penting yang berperan dalam GPPH. Suatu penelitian menunjukkan bahwa anak dengan ibu yang bekerja di luar rumah sehingga pengasuhan anak mereka diserahkan kepada pembantu rumah tangga memiliki risiko lebih besar untuk mengalami gejala hiperaktif yang berat ${ }^{13}$. Berbagai laporan dalam sosiodemografis 
menyatakan bahwa prevalensi GPPH lebih tinggi pada anak-anak dengan keluarga yang dipimpin oleh ibu tunggal (single mother). Laporan sosiodemografis tersebut juga menjelaskan bahwa dari 61779 anak GPPH, diantaranya terdapat 5028 anak yang memiliki >3 komorbid dan memiliki stuktur keluarga dengan ibu tunggal (22\%), orang tua adopsi (16\%) dan lain-lain $21 \%{ }^{6}$.

Faktor Postnatal dalam penelitian ini menunjukkan persentase 33\%, dan lebih tinggi daripada anak GPPH dengan komorbiditas. Hal ini juga selaras dengan komorbiditas terbanyak GSA yang tidak didapatkan etiologi dan faktor resiko berupa adanya riwayat kejang demam dan riwayat trauma kepala yang dapat membuat GSA tersebut bisa timbul.

Hal ini menunjukkan bahwa semua anak GPPH tanpa komorbiditas (18 kasus) memiliki pengasuhan total yang sehari-harinya bersama dengan kedua orang tua lengkap, tinggal di satu rumah yang sama atau bukan di penitipan. Hasil tersebut selaras dengan prognosis anak yang tidak menjadi lebih buruk oleh karena senantiasa adanya dukungan dan edukasi oleh orang tua.

\section{KESIMPULAN DAN SARAN}

\section{Kesimpulan}

Sebanyak 18 (21\%) pasien anak GPPH tanpa komorbid, 52 (62\%) memiliki 1 komorbid dan sebanyak $14(17 \%)$ pasien yang memiliki >1 komorbid. Komorbiditas terbanyak yaitu gangguan spektrum autisme sebanyak 28 (35\%) kasus. Jenis gangguan $>1$ komorbid terbanyak yaitu gangguan berbicara dan berbahasa + retardasi mental sebanyak 4 (29\%) kasus. Faktor risiko yang paling menonjol dari pasien anak GPPH dengan komorbiditas adalah faktor natal (39\%) dan faktor pengasuhan parsial (18\%). Faktor risiko yang paling menonjol dari pasien anak GPPH tanpa komorbiditas adalah faktor postnatal dengan persentase $33 \%$ dan tidak didapatkan kasus faktor pengasuhan parsial. Manfaat dari studi ini adalah dengan mengetahui adanya komorbiditas diharapkan evaluasi awal yang cermat harus dilakukan saat diagnostik untuk mengeliminasi berbagai kemungkinan diagnosa banding dan diharapkan juga komorbiditas yang menyertai
GPPH dapat ditangani dengan baik sehingga prognosis dari pasien tidak berakhir buruk.

\section{Saran}

1. Perlu dilakukan penelitian selanjutnya yang menunjukkan hubungan secara analitik.

2. Diperlukan kerjasama yang baik antara kelembagaan, klinisi, masyarakat dan pihakpihak terkait lainnya dalam penanganan GPPH beserta komorbiditasnya.

\section{DAFTAR PUSTAKA}

1. Saputro, D. (2009). ADHD (Attention Deficit/Hyperactivity Disorder). Jakarta: CV. Sagung Seto.

2. Elvira, S., \& Hadisukanto, G. (2017). Buku Ajar Psikiatri (3 ed.). Jakarta: Badan Penerbit Fakultas Kedokteran Universitas Indonesia.

3. Soetjiningsih, \& Ranuh, I. (2013). Tumbuh Kembang Anak (2nd ed.). Jakarta: EGC.

4. Ratnasari, N., Kaunang, T., \& Dundu, A. (2016). Komorbiditas pada Anak Gangguan Pemusatan Perhatian dan Hiperaktivitas (GPPH) pada 20 Sekolah Dasar di Kota Manado. Jurnal E-Clinic $(e C l), 41$.

5. Masi, L., \& Gignac, M. (2015). ADHD and Comorbid Disorders in Childhood Psychiatric Problems, Medical Problems, Learning Disorers and Developmental Coordination Disorder. Clinical Psychiatry.

6. Larson, K., Russ, S., Kahn, R., \& Halfon, N. (2011). Patterns of Comorbidity, Functioning, and Service Use for US CHildren With ADHD. American Academy of Pediatrics.

7. Faraone, S., \& Kunwar, A. (2007, May 3). ADHD in Children With Comorbid Conditions: Diagnosis, Misdiagnosis, and Keeping Tabs on Both. Retrieved March 15, 2019, from Medscape: https://www.medscape.org/viewarticle/555748_ 7

8. Patel, N., Patel, M., \& Patel, H. (2011). University of Missouri Health Care, USA. Retrieved October 5, 2015, from ADHD and Comorbid Conditions: http://cdn.intechopen.com/pdfs wm/280240.pdf

9. Leiner Y. (2014). The co-occurence of autism and attention deficit hyperactivity disorder in children- what do we know? Frontiers in Human Neuroscience, 8, 1-8.

10. Kementerian Kesehatan RI. (2011). Anak Berkebutuhan Khusus. Jakarta 
11. Soetjiningsih, \& Ranuh, I. (2013). Tumbuh Kembang Anak (2nd ed.). Jakarta: EGC

12. Masi, L., \& Gignac, M. (2015). ADHD and Comorbid Disorders in Childhood Psychiatric Problems, Medical Problems, Learning Disorers and Developmental Coordination Disorder. Clinical Psychiatry.

13. Indriyani, S., Soetjiningsih, S., Ardjana, I. E., \& Windiani, I. T. (2008). Prevalensi dan FaktorFaktor Risiko Gangguan Pemusatan Perhatian Anak dan Hiperaktivitas di Klinik tumbuh Kembang Anak RSUP Sanglah Denpasar. Sari Pediatri, 9(5). 